\title{
MULHERES POSSÍVEIS: A CONSTRUÇÃO SOCIAL DA MULHER NAS EXPERIÊNCIAS DA TRANSEXUALIDADE
}

\author{
Hugo Felipe Quintela*
}

RESUMO

A proposta central deste trabalho é, a partir de uma análise socioantropólogica, refletir e apresentar alguns elementos que colaboram na construção social de se compreender como mulher nas experiências da transexualidade, levando em consideração o processo de socialização existente na sociedade ocidental, processo esse que modela as nossas subjetividades por meio de binarismos de gênero e do corpo. Para tanto, desde 2012 tenho entrevistado mulheres transexuais na tentativa de conseguir compreender como são os elementos recorrentes nesse processo de construção do ser mulher a partir de uma experiência constantemente questionada e deslegitimada, como é a experiência da transexualidade em nossa sociedade. A partir do método História de Vida, pude perceber nas trajetórias dessas mulheres experiências comuns e outras que eram peculiares a cada trajetória, mas em todos os relatos apareciam, sobretudo, situações de negligências por parte de instituições estruturantes de nossa sociedade, a saber: a família, a escola e a igreja. Em suma, nas histórias de vida dessas mulheres é notória uma busca constante do "se pensar como mulher", assim como nos relatos diversos percebe-se o não reconhecimento dessa experiência como sendo possível, pois a nossa sociedade constantemente tenta colocá-las no que eu denominei de liminaridade permanente.

Palavras-chave: Transexualidade. Gênero. Mulheres transexuais. Liminaridade permanente.

Possible women: social constitution of women in transexual experiences

\section{ABSTRACT}

Through social-anthropological analysis, the main purpose of this paper is to try to understand how women are socially constituted in transexual experiences, taking into consideration all the socialization process that there is in Occidental society. This socialization models our subjectivity using gender and body binarism. For that, since 2012, I have been interviewing transexual women, trying to understand what elements are recurrent in this women-construction process. Moreover, we also consider that this process in constantly questioned and illegitimate as it is the transexual experience in our society. Taking Life History as a method, I could see that these women lifelines have similar and specific experiences of negligence from structural social institutions, for e.g. family, school and church. Briefly, these women lifelines revealed the constant search of a "thinking as a woman" idea, as so as many testimonials of social unrecognizing of these experience. Our society is constantly trying to fit these women in something I call the "Permanent Liminality".

Keywords: Transsexuality. Gender. Transsexual women. Permanent Liminality.

Mujeres posibles: la construcción social de la mujer en las experiencias de la transexualidad.

RESUMEN

La propuesta central de este trabajo es, a partir de un análisis socioantropólogico, intentar comprender

*Hugo Felipe Quintela é doutorando em Ciências Sociais pelo Programa de Pós-Graduação em Ciências Sociais UFJF, Mestre em Ciências Sociais pelo Programa de Pós-Graduação em Ciências Sociais UFES. Professor de Sociologia no Instituto Federal de Espírito Santo. 
cómo se da la construcción social de la mujer en las experiencias de la transexualidad, teniendo en cuenta todo el proceso de socialización que existe en la sociedad occidental, proceso ese que modela nuestras subjetividades por medio de los binarios del género y del cuerpo. Para ello, desde 2012, vengo entrevistando a las mujeres transexuales, en un intento de llegar a entender cómo son los elementos recurrentes en el proceso de construcción del ser mujer a partir de una experiencia constantemente cuestionada y deslegitimada, como es la experiencia de transexualidad en nuestra sociedad. A partir del método Historia de la Vida, pude notar en las trayectorias de esas mujeres experiencias comunes y otras que eran peculiares a cada trayectoria, pero en todos los relatos aparecían, sobre todo, situaciones de negligencia de instituciones sociales estructurantes de nuestra sociedad, a saber: familia, escuela y la iglesia. En suma, a partir de las historias de vida de esas mujeres, es notorio una constante búsqueda del "pensarse como mujer», así como varios relatos sobre el no reconocimiento de esa experiencia como siendo posible, porque nuestra sociedad constantemente intenta ponerlas en el que yo llamé de liminaridad permanente.

\section{Palabras clave: transexualidad. Género. Mujeres transexuales. Liminadidad permanente.}

\section{Introdução}

A proposta central deste trabalho é refletir, sobretudo numa perspectiva antropológica, as experiências advindas da transexualidade na sociedade ocidental contemporânea, especialmente na sociedade brasileira, tendo como elementos para análise os relatos das trajetórias de vida de quatro mulheres transexuais, residentes na região metropolitana do Estado do Espírito Santo. Para tal reflexão, partimos do pressuposto de que a experiência transexual é plural, ou seja, não é possível definirmos um único conteúdo simbólico ou identitário para ela. Então, precisamos compreender a existência de transexualidades. Logo, o que talvez seja possível dizermos é que essa experiência é produtora de inúmeras situações (impedimentos, estigmas e discriminações, que são produtos do significado social aplicado a ela), que são partilhadas por um número muito expressivo de pessoas que a vivenciam. Assim, o que será proposto como reflexão ao longo deste texto é apenas uma das várias possibilidades de compreensão sobre a transexualidade, por isso tal reflexão pode (ou deve) ser compreendida como um rascunho, uma vez que essa experiência é, como já dito, plural, dinâmica e cheia de matizes.

Tomando como referência central - mas não só - os relatos das mulheres apresentados mais adiante, penso que a expressão "quase lá" define de forma apropriada suas experiências de ser mulher a partir da transexualidade. Essa expressão, "quase lá", define não só as experiências das interlocutoras deste trabalho, mas também de inúmeras mulheres transexuais no Brasil e em inúmeros outros países. São muitos os casos noticiados de mulheres transexuais que, cotidianamente, são alvos de diferentes tipos de violência, sejam eles físicos, psíquicos e/ ou simbólicos. Toda essa situação condiciona essas mulheres a um lugar social que proponho denominar como um "lugar liminar", visto que essa liminaridade é vivenciada, principalmente, em decorrência do binarismo sexual dos corpos que permeiam a compreensão hegemônica ocidental moderna sobre as possibilidades de experienciar gênero, corpo e sexualidade. Michel Foucault nos ajuda a compreender essa questão quando diz que a sexualidade torna-se referência fundamental no processo de produção da verdade e da subjetividade dos indivíduos na era moderna, pois segundo ele a atividade sexual produz uma inquietação mais intensa, sendo problematizada, cada vez mais, em termos patológicos e morais.

[...] segundo círculos cada vez mais estreitos, o projeto de uma ciência do sujeito começou a gravitar em torno da questão do sexo. A causalidade no sujeito, o inconsciente do sujeito, a verdade do sujeito no outro que sabe, o saber, nele, daquilo que ele próprio ignora, tudo isso foi possível desenrolarse no discurso do sexo. Contudo, não devido a alguma propriedade natural, inerente ao próprio sexo, mas em função das táticas de poder imanentes a tal discurso (FOUCAULT, 1980, p. 68-69).

De muitos modos, por meio de barreiras diversas, essas mulheres são impedidas de 
atravessar um conjunto de construções sociais que define, de forma hermética, o que vem a ser uma mulher ou um homem. Essa realidade é bem explicitada pela militante transfeminista e diretora do Fórum da Juventude LGBT Paulista, Daniela Andrade, que disse em entrevista à Revista Fórum ${ }^{1}$ :

Essas pessoas estão marginalizadas, alijadas dos bancos das escolas e universidades, preteridas no mercado de trabalho, sendo forçadas a se prostituírem, tendo o gênero deslegitimado diuturnamente, sendo agredidas por uma sociedade que não nos considera gente, que não vê humanidade em nós.

Isadora Otoni, em artigo também para a Revista Fórum ${ }^{2}$, aduz que o preconceito afasta as pessoas transgênero da escola, reduz oportunidades de trabalho e as condiciona à experiência da prostituição como a única opção de trabalho viável. Otoni traz em seu artigo relatos de pessoas que vivenciam a transexualidade, dentre elas mulheres, e pontua que:

A transfobia é um dos preconceitos mais generalizados dentro da sociedade. Não é raro casos de movimentos feministas e LGBT que excluem as transexuais de suas pautas. Para Daniela Andrade, a agenda de travestis e transexuais é abordada "de forma precária e negligente" pelo movimento LGBT. Já Cris, que mora em Campo Grande, denuncia que a parcela elitizada dos homossexuais trata as pessoas trans como "subumanas e subalternas", e não respeita a identidade de gênero. A respeito das feministas, ela ressalta que parte delas acaba sendo machista: Parece que a mulher se resume a uma vagina, quando na verdade a mulher é muito mais que isso. A mulher não é necessariamente isso e muito menos só isso. Você não nasce homem ou mulher, você torna-se homem ou mulher conforme o seu comportamento social, aquilo que você assume como identidade.

É importante pontuar que ser mulher é uma experiência que se diferencia ao longo do tempo, no espaço geográfico, nas classes sociais, ou seja, é uma experiência histórica, cultural e socialmente heterogênea. Por exemplo, ser mulher no sertão nordestino é diferente de ser mulher num bairro de classe média no sudeste brasileiro, embora existam regras que estabeleçam um mínimo de coerência para todas as performances femininas. Tal exemplificação nos ajuda a perceber que, por mais que exista uma dimensão biológica relevante, que insiste ser invocada para condicionar as identidades de gênero aos corpos biológicos, ela não é e nunca será capaz de dar conta de explicar a plasticidade humana em produzir as diversas identidades de gênero. Logo, ser mulher (ou ser homem) é uma experiência que tem como lugar de habitação não o corpo generificado, mas um corpo que é cultural, um "corpo mundo". É uma experiência desenhada pela classe, pela cultura, pela idade, pela raça e pela geração, ou seja, ela existe e é sustentada a partir da interação de elementos socioculturais que são significativos para uma determinada sociedade. Segundo Foucault (1982, p. 22), o corpo, "lugar de dissolução do eu", "volume em perpétua pulverização", traz consigo "em sua vida e em sua morte, em sua força e em sua fraqueza" a inscrição de todos os acontecimentos e conflitos, erros e desejos. O corpo biológico é usado como cerceador das experiências das identidades de gênero, desse modo, ao longo do texto, ver-se-á o termo "mulher na transexualidade" ser usado reiteradamente. Optei em propor esse termo, pois entendo que transexualidade é um "lugar" possível de ser mulher (ou homem), mas não é o lugar de referência e nem aceitável para nossa sociedade. Ser mulher na transexualidade é uma experiência que se dá sob a ótica do comportamento estigmatizado e desviante, tomando como referência a obra de Becker (2008), Goffman (1988) e Elias e Scotson (2000).

$\mathrm{O}$ adjetivo transexual, em nossa sociedade, tende a produzir nas interações sociais a deslegitimação da experiência de ser mulher e, por isso, a máxima "isso não é mulher de verdade"

1 Entrevista disponível no link: <http://www.revistaforum.com.br/blog/2014/01/a-sociedade-nao-nos- considera-gente-diz-ativista-transexual/>. Acesso em: 25 jan. 2018.

2 Entrevista disponível no link: <http://www.revistaforum.com.br/digital/132/sem-emprego-para- trans/>. Acesso em: 25 jan. 2018. 
é muito comum nas trajetórias de mulheres na transexualidade. A "verdade" que geralmente é invocada nessa máxima está localizada no corpo binário, como apontado por Laqueur (2001). Um corpo que, interpretado sob um discurso muitas vezes de cunho biologicista, mas não só, que localiza os indivíduos em categorias sociais rígidas a partir das genitálias. Romper essa estrutura heteronormativa e binária dos corpos é quase sempre uma experiência modelada por conflitos e muitos embates.

A experiência do "quase lá" é produzida, principalmente, porque o "campo de possibilidades" (VELHO, 2008) de "ser mulher" em nossa sociedade é limitado, como já dito, por uma noção de gênero e de corpos heteronormativo e binário. Para superar esse campo de possibilidades restrito e impeditivo, é necessário superar as noções cristalizadas sobre sexo e gênero, como propõe Butler (2003). Ainda temos um longo caminho para que essa lógica existente seja superada, e, assim sendo, diariamente inúmeras mulheres na transexualidade recorrentemente estão "quase lá" nessa trajetória de serem socialmente reconhecidas como uma mulher.

Sobre as relações sociais que se estabelecem pelas normas do gênero, Butler (2003) trabalha com o conceito de gênero e todos os seus desdobramentos no que se refere às relações de poder e o impacto deste nas mudanças sociais. Butler traz uma denúncia a respeito da instável noção das identidades existentes em nossa sociedade, além de desnaturalizar a binaridade dos gêneros masculino e feminino naturalizada no mundo ocidental. A filósofa ainda traz luz sobre a estrutura de poder que determina a aceitação ou a negação de identidades e de práticas sexuais. Butler, em sua teoria, mostra que devem ser tratadas e percebidas também como socialmente legítimas as manifestações de gênero e sexuais consideradas divergentes em nossa sociedade.

Um ponto importante da teoria dessa autora é que ela retira a ideia de que o conflito é produzido no sujeito (discurso médico) e transfere esse conflito para as normas de gênero, nos mecanismos originados histórica e socialmente, e que criam identidades patologizadas. Butler retoma os escritos de Laqueur, quando este faz uma análise histórica da questão de gênero, para também mostrar que, até o século XVIII, a distinção entre os corpos masculino e feminino existia de uma maneira diferenciada, mostrandose mais em uma relação de continuidade. $\mathrm{O}$ discurso dominante era do isomorfismo, ou seja, os corpos masculino e feminino eram versões hierarquicamente ordenadas de um mesmo sexo. Segundo Laqueur, só a partir do XIX que esses corpos masculinos e femininos, baseados no modelo reprodutivo, foram compreendidos como sendo profundamente diferentes. Foi nesse período que os órgãos genitais passaram a ser marcas da diferença sexual entre homens e mulheres.

Apesar de ser vivenciada por diversas sociedades e em diversas épocas ao longo da história (BRANDÃO, 2011; SAADEH, 2004; THÉVET, 1944; CHILAND, 2008; ARMANTINO, 2011, TREVISAN, 2002; MOTT, 2012; CLASTRES, 2003), é na sociedade ocidental atual que a transexualidade foi patologizada e, por consequência, foi incorporada ao discurso hegemônico das ciências biomédicas.

Como bem pontuou Cossi (2011), coube à Medicina, destacadamente a dos meados do século $\mathrm{XX}$, ter elevado a experiência da transexualidade à categoria de entidade patológica, principalmente a partir dos estudos de Harry Benjamin, John Money e Robert Stoller. Desde então, a cirurgia de transgenitalização ${ }^{4}$ se estabelece como a única possibilidade institucionalizada não só de "adequação" corporal, mas também moral e social das pessoas que vivenciam a transexualidade. Assim, proponho interpretar essa cirurgia como um "rito de passagem" obrigatório e institucionalizado pelo Estado para que pessoas que vivenciam a transexualidade possam ter a plenitude da sua existência. Todavia, o que se pode perceber, numa grande parcela de experiências relatadas, é que a cirurgia não consegue fazer com que as

4 No Brasil a cirurgia de redesignação sexual iniciou na década de 1970, mas só foi autorizada a partir da Resolução CFM n. 1.482, de 10 de setembro de 1997, a título experimental, sendo apenas com a Resolução CFM n.1.652, de 6 de novembro de 2002 que a cirurgia de neocolpovulvoplastia (cirurgia que transforma pênis em vagina) deixa de ser considerada experimental. 
pessoas transexuais superem a experiência do "quase lá". Ela promove mudanças corporais, mas quase sempre as restrições e impedimentos socioculturais de conseguir a satisfação psicossocial permanecem. E é por esbarrar num campo de possibilidade heteronormativo que a mulher na transexualidade vivenciará o que denominarei a partir de agora neste artigo de liminaridade permanente. Saliento que tomo como definição da experiência da transexualidade aquela proposta por Berenice Bento:

Sugiro que a transexualidade é uma experiência identitária, caracterizada pelo conflito com as normas de gênero. Essa definição se confronta com a aceita pela medicina e pelas ciências psi que a qualificam como uma "doença mental" e a relaciona ao campo da sexualidade e não ao gênero (BENTO, 2008, p.18).

Com a metodologia da História de Vida, foram selecionados para compor o corpus deste trabalho os relatos de vida de quatro mulheres na transexualidade - Sandy, Deborah, Crislaine e Rafaela -, residentes da Grande Vitória, região metropolitana do Estado do Espírito Santo.

As reflexões, proposições e indagações presentes neste texto são frutos de pesquisas iniciadas desde 2012 sobre as experiências da transexualidade, especialmente as de mulheres, que são produzidas e vivenciadas na sociedade brasileira. O material empírico presente neste trabalho corresponde a entrevistas realizadas entre os anos de 2012 a 2015.

Nesse período, essas quatro mulheres na transexualidade narraram suas experiências da infância até o momento atual de suas vidas a mim por meio de entrevistas semiestruturadas e em diversos encontros. Assim, a partir das suas vivências cotidianas, pode ser percebida a relevância de instituições como família, escola e religião nas construções de si como mulheres.

A condição metodológica e analítica basilar deste trabalho são experiências cotidianas de mulheres na transexualidade. São as suas narrativas que tiveram importância para a construção desta pesquisa. Foram suas histórias, seus relatos de vidas que fomentaram a interpretação sobre como é a experiência de ser uma mulher na transexualidade em uma sociedade que inviabiliza essa possibilidade de se experimentar outras formas de ser mulher.

\section{1- A Transexualidade e a "Liminaridade Permanente"}

Não ser permitida entrar no banheiro feminino; ter o nome social reconhecido em instituições públicas; ser discriminada em locais públicos; ser expulsa de casa logo nos primeiros anos da adolescência; sofrer agressões físicas de estranhos e de familiares. Essas são algumas das diversas experiências vivenciadas cotidianamente por inúmeras mulheres transexuais na sociedade brasileira. Se a violência contra gays, lésbicas e bissexuais é intensa no Brasil, ela ganha uma expressão muito mais acentuada com as pessoas trans ${ }^{5}$, sejam elas transexuais ou travestis. Devese ressaltar que, assim como ser homem ou ser mulher, a transexualidade e a travestilidade também são experiências identitárias construídas social e culturalmente. Todavia, como já mencionado, as experiências identitárias trans se configuram a partir da resistência às normas de gênero e, portanto, são marginalizadas socialmente, fazendo com que as pessoas que as vivenciem fiquem vulneráveis a violências físicas e/ou simbólicas.

Algumas pesquisas feitas com nãoheterossexuais (IRIGARAY, 2007; FERREIRA \& SIQUEIRA, 2007; SIQUEIRA et all., 2009; GARCIA E SOUZA, 2010; IRIGARAY, SARAIVA E CARRIERI, 2010; SOUZA \& PEREIRA, 2010; IRIGARAY \& FREITAS, 2009) deixam evidente a discriminação, o preconceito, a homofobia, a valorização da heteronormatividade, a desigualdade no tratamento, a dificuldade de crescimento na carreira. As experiências trans, nesse ínterim, intensificam as diversas violências que emanam do não cumprimento das normas socialmente estabelecidas sobre os gêneros, o corpo e a sexualidade.

Desse modo, entendo que a liminaridade

5 Entendo como experiência trans toda experiência que rompe com a noção dicotômica e rígida existente, especialmente na sociedade ocidental, do sexo e do gênero, e que enseja novas corporalidades e subjetividades. 
permanente é o fator que acentua e/ou produz as diversas experiências negativas nas vidas de mulheres transexuais. E para tal argumento ser sustentado é necessário entendermos o que é abordado neste trabalho como liminaridade. Para tal compreensão do conceito proposto aqui é primordial compreender a importância dos ritos de passagem na dinâmica da vida social.

De antemão, é tributado o conceito antropológico de liminaridade ao antropólogo Arnold Van Gennep; posteriormente, esse conceito será retomado e aprofundado por Victor Turner. Van Gennep e Turner desenvolveram esse conceito dentro dos estudos sobre ritos de passagem. Sendo assim, para a compreensão da transexualidade como uma experiência produtora da liminaridade permanente, é importante enfatizarmos que a cirurgia de transgenitalização é colocada como mecanismo institucional do Estado para que pessoas que vivenciam a transexualidade se "adequem" às categorias sociais existentes. Por isso, proponho considerar que a tal cirurgia ganha um status de um rito de passagem, estatal e obrigatório, sobretudo pelo discurso hegemônico da biomedicina, para que quem vivencia a experiência da transexualidade em nossa sociedade possa ser enquadrado dentro de uma perspectiva de normalidade construída sob as noções do binarismo dos corpos e do gênero.

Levando em consideração $o$ aspecto importante dos ritos de passagem para se entender as relações entre os indivíduos, os grupos e as posições em determinado contexto social, Van Gennep (1978) argumenta sobre a importância de se analisar o sistema social como dinâmico e compartimentalizado por uma série de rituais que definiriam os grupos e as divisões entre os indivíduos. A partir desse autor, a trajetória dos sujeitos estaria permeada de ininterruptas passagens de uma posição social para outra. Dessa forma, a compreensão dos ritos, regidos pela decisão coletiva e dotados de tempo e de espaço, se caracteriza pela necessidade do indivíduo de promover uma transformação no mundo social no qual vive e em si mesmo, com o intuito de viver em sociedade.

Em resumo, Van Gennep (1978) compreende a primeira fase dos ritos de passagem - separação - como a que abrange o simbolismo que significa o afastamento do indivíduo tanto de um grupo quanto de um conjunto de condições culturais, ou mesmo de um ponto fixo anterior da estrutura social. Já a segunda fase - margem ou limiar - é aquela cuja ambiguidade é marca característica do sujeito ritual, tendo em vista que esse sujeito passa por um domínio cultural em que há poucos, ou quase nenhum, dos atributos do passado ao do estado futuro. Por fim, a terceira e última fase - agregação ou reagregação - é aquela em que a passagem é consumada. Uma vez que o rito é consumado, o sujeito ritual ganha relativa estabilidade, tendo ele que obedecer a certas obrigações e direitos claramente estabelecidos pela estrutura.

Victor Turner (1974) nos revela que o modelo da nossa sociedade é o de uma "estrutura de posições" e que devemos encarar o período de margem ou liminaridade como uma situação interestrutural. Ele ainda considera que os ritos de passagem estão presentes em todas as sociedades, assinalando transições entre estados, que seria, em sua definição, "uma condição relativamente fixa ou estável". Para esse autor, o termo "estado" é aplicável às condições ecológicas ou à condição física, mental ou emocional em que uma pessoa ou um grupo se encontra num determinado momento.

De acordo com esse autor, no estágio limiar as pessoas se encontram em situações de ambiguidade, pois elas estariam fora das estruturas sociais, não fazendo parte de nenhuma posição socialmente estabelecida. Dessa maneira, a liminaridade seria comparável à morte. Turner ainda enfatiza que a morte ritual, vislumbrada em inúmeros ritos de passagem, seria a forma de estabelecer o elo do estágio limiar (um estágio de morte) com a "nova" pessoa que surgiu depois do rito de passagem, um tipo de nascimento ou renascimento. Assim sendo, o estado limiar seria um "corte" brusco entre o antigo e o novo, entre o antigo estado da pessoa ou do grupo e o novo estado (status) dessa pessoa ou grupo.

A partir da obra de Turner (1974), compreendemos a liminaridade como o momento alto no ritual, pois a estrutura social se encontra em suspensão e, por isso, existe a ausência de "status", de diferença sexual, de classes, de hierarquia, de obrigações de parentesco. No momento liminar, os corpos ocupam um espaço- 
tempo indizível, o indivíduo se localiza no meio, no entre (betwixtandbetween) ${ }^{6}$, no limbo, no "nada" da estrutura cotidiana, pois o que se suspende é todo o sistema social vigente, o ordinário social, as vivências cotidianas. Por isso, Turner chamou a liminaridade de prima matéria: um estado bruto, em que os indivíduos não estão nem dentro nem fora da sociedade, é um lugar onde se está absorto em singularidades, espaços e tempos inclassificáveis. O autor ainda aduz que esse lugar liminar é transporte para outras realidades.

Nesse sentido, penso ser possível compreender a experiência da transexualidade como um momento de liminaridade em nossa sociedade, mais ainda entendo essa experiência sendo como uma liminaridade permanente, tendo em vista que, ao ser enquadrada pelo discurso biomédico, a experiência transexual ganha um caráter liminar, uma vez que indivíduos que vivenciam essa experiência são colocados "fora do mundo". De acordo com Van Gennep (1978, p. 26), “Toda alteração na situação de um indivíduo implica aí ações e reações que devem ser regulamentadas e vigiadas, a fim de a sociedade geral não sofrer nenhum constrangimento ou dano".

Tomando como referência o conceito de cultura proposto por Clifford Geertz (1978), a cultura como teia de significados, podemos colocar o gênero como uma das teias importantes que significam as vivências dos sujeitos contemporâneos, estabelecendo significados e padrões para as expressões corporais e comportamentais das pessoas, o que nos possibilita entender o porquê do sentimento de inadequação dos sujeitos transexuais, uma vez que, em nossa cultura, o corpo sempre é referenciado, ou seja, significado em relação à heteronormatividade, o que faz com que o corpo nasça "generificado". Como coloca Cossi (2011, p.88), "no momento em que se identifica o sexo do bebê, produz uma invocação performativa; expectativas e suposições são materializadas (cores, brinquedos, modelos de roupas e projetos futuros já são imputados ao recém-nascido)". Logo, desde tenra idade, somos emaranhados nas "teias do gênero", teia essa que é estruturante das nossas relações sociais. Ser envolto por ela para uns é uma experiência de inclusão, mas para outros, de exclusão.

Para uma pessoa transexual, ser envolto por essa "teia" é motivo de exclusão e para que ela seja incluída é necessário passar por um rito de passagem. Portanto, entendo que esse rito de passagem, que permite à pessoa transexual retornar para o mundo novamente com novos papéis sociais institucionalizados (nesse caso seriam os papéis de mulher ou homem), seria a cirurgia de transgenitalização. Segundo o discurso biomédico, é só a partir da cirurgia que ela seria retirada desse não-lugar, no qual ele é compreendido como "não-gente". Nesse sentido, considero importante se pensar, assim como Le Breton (2004), que as modificações corporais são indicadores de ritos de passagem, a fim de mudança de status do sujeito em determinado contexto social.

Pela lógica biomédica, a pessoa que vivencia a transexualidade sofre de uma inadequação. De maneira pontual, esse indivíduo rompe com as estruturas vigentes em nossa sociedade, em relação ao corpo e aos gêneros. Velho (1999) compreende que, no Brasil, tratar o límem e o paradoxal como negativos seria incoerente, chegando a apontar que entre nós as celebridades trans não são objetos de horror ou de abominação, como acontece nos EUA.

Realmente, ao tratarmos da sociedade brasileira, com suas diversas realidades sociais convivendo entre si, entrecruzando-se, há uma institucionalização do intermediário que modela a sociabilidade (VELHO, 1999). Por isso, é complicado entendermos a liminaridade apenas com o teor negativo. Todavia, o fato de indivíduos que estão na liminaridade não serem objetos de horror, como o caso das pessoas que vivenciam a transexualidade, não as fazem estar plenamente inseridas na sociedade. Ou seja, a liminariedade não é boa em si, depende da direção que tomamos durante o trânsito. Existem trânsitos legítimos (o calouro na faculdade, o aprendiz no emprego), mas outros são abominados, como o caso em tela.

6 Turner usa o termo "betwixtandbetween" em vários livros, no qual funde dois sinônimos que aponta a indeterminação e a falta de localização precisa da coisa designada. Exemplos de possíveis traduções seriam: "nem lá nem cá", "aquém e além dos pontos fixos", "entre dois mundos", "entre e entrementes". 
Turner (1974) nos diz também que a identidade liminar é vivenciada no âmbito da experiência corporal, na forma de um corpo liminar: um corpo que se nega a identificarse com uma estabilidade social fixa, buscando seu próprio movimento interno $\mathrm{e}$ outras possibilidades de relação com o mundo, vivência corporal típica das mulheres na transexualidade.

Por isso, ao tratarmos do lugar social da mulher na transexualidade em nossa sociedade, podemos perceber que o rito de passagem, embora institucionalizado pelo discurso médico e jurídico, não consegue promover a sua agregação na sociedade. É possível entender que, em vários momentos e/ou fases da vida, ela ocupa o lugar liminar em nossa sociedade, já que, muitas vezes, é na infância, por apresentarem o rompimento com as teias do gênero, que as interlocutoras desta pesquisa foram colocadas na liminaridade. Mas é perceptível que, ao longo de suas trajetórias, essas mulheres criaram estratégias e mecanismos de sair desse lugar liminar para o qual elas tendem a ser empurradas.

O que sugiro é que a liminaridade permanente é uma experiência existente e significativa na vida de muitas pessoas transexuais, mas não necessariamente vividas ou sentidas por todas. Proponho o adjetivo permanente, pois na abordagem clássica dessa experiência de liminaridade, seria um momento pontual e específico pelo qual indivíduos dentro de seu grupo social passariam para poder ter acesso a uma nova identidade e, por consequência, um novo status social. Sendo assim, ele seria transitório e não constante. A liminaridade não é uma experiência exclusiva de pessoas transexuais, mas vivenciá-la de forma permanente ou recorrentemente talvez seja algo bem particular na trajetória de pessoas transexuais.

Enquanto categoria de interpretação da dinâmica social, a liminaridade só existe porque em algum momento ocorreu a separação e aconteceráa agregação.Somenteháa possibilidade da separação de indivíduos quando estes, em algum momento, estavam incluídos e, por isso, tinham o reconhecimento no seu contexto social.
Já a agregação é o que possibilita a superação da condição liminar e a reinserção no contexto social como indivíduos reconhecidos e legítimos dentro do contexto social. A liminaridade permanente não pressupõe a agregação; na verdade, ela é permanente por não haver a possibilidade de agregação. A ideia da agregação está relacionada com a noção de reconhecimento. Como veremos nos relatos abaixo, a lembrança de não se perceber incluída no contexto social é algo que se dá nas lembranças dos primeiros anos de vida. Não é possível separar aquilo que não foi incluído.

\section{2 - Biografias Liminares de Mulheres na transexualidade}

A primeira mulher na transexualidade que entrevistei foi Sandy, uma produtora cultural e atriz capixaba. Nascida em 1972, na cidade Vila Velha, filha única de uma família de classe média baixa, Sandy Vasconcelos viveu boa parte da sua vida na cidade de Cariacica, região metropolitana de Vitória. Em agosto de 1998, com 26 anos, Sandy, a partir de sua luta travada junto às autoridades competentes, conseguiu realizar a cirurgia de transgenitalização. Tornouse a primeira pessoa a realizar essa cirurgia no Espírito Santo e a segunda no Brasil. Faz questão de enfatizar que foi graças à sua luta individual, iniciada desde 1996, que muitas pessoas têm conseguido realizar o sonho da redesignação sexual. Conta que os esforços dela e de Bianca Magro $^{7}$ foram extremamente importantes para que a legislação brasileira mudasse em relação à cirurgia de redesignação sexual.

Em 2001, Sandy decidiu mudar-se para a Europa, com o objetivo de buscar o anonimato que a midiatização da sua cirurgia no Estado do Espírito Santo lhe tinha tirado. Em Portugal, procurou construir uma vida na qual ela não fosse percebida como uma mulher diferente - nas suas próprias palavras, ela queria viver "fora dos olhares do picadeiro". Sandy, em seu novo país, era reconhecida como mulher, sem o adjetivo transexual, e se casou em território europeu, tendo seu passado compartilhado apenas com

7 A primeira mulher na transexualidade oficialmente reconhecida pelo Conselho Federal de Medicina, operada poucos meses antes de Sandy, em São Paulo. 
seu marido.

Depois de dois anos residindo em terras portuguesas, Sandy foi surpreendida com a exposição da sua história numa rede de televisão local, que havia comprado o programa SBT Repórter, para o qual ela havia dado entrevista no Brasil. Essa aparição surpresa em um programa no horário nobre em Portugal rendeu a ela muitos problemas, pois ninguém, além do seu marido, sabia da sua história e, por isso, ela começou a sofrer preconceitos nos seu convívio social. Ela conta que teve muitos problemas, inclusive, com a família do seu marido.

Atualmente, Sandy está separada e voltou a morar no Brasil, atuando como produtora artística em Vitória. Sua decisão de retornar ao Brasil se deu por sua separação, além da crise econômica vivida pela Europa. Em Vitória, Sandy voltou a trabalhar no meio artístico, desenvolvendo vários trabalhos, tanto no teatro quanto no cinema, sendo no ano de 2013 premiada no $20^{\circ}$ Vitória Cine Vídeo, com o troféu Marlin Azul pelo curta Você Suportaria?. Sua carreira também é composta por vários trabalhos como atriz em produções estaduais.

Minha segunda entrevistada foi Deborah. Nascida em Vitória, em 1980, Deborah viveu parte da sua infância no bairro Santa Marta, periferia da cidade de Vitória, em um lar evangélico, de uma família de nove filhos, sendo ela uma das mais novas. Recorda que, quando criança, ficava ao encargo dos irmãos mais velhos ajudarem no cuidado dos mais novos, dessa forma, além da educação severa de seus pais, ela também sofria com o autoritarismo dos irmãos mais velhos.

Sua infância é marcada por recordações, muitas delas relacionadas às dificuldades de sua família em compreendê-la. Um dos fatos marcantes na infância de Deborah foi o atropelamento que ela sofreu ao brincar na rua com seus amigos, por volta dos seis anos. Apesar de o atropelamento ter sido acidental, ela recorda que, na época, já era tratada como diferente das outras crianças e por essa diferença é que, segundo ela, muitas pessoas transferiram a culpa de tal acidente a ela própria. Conta que ouvia coisas do tipo: "se ele estivesse brincando com os meninos no campo de futebol e não na calçada com as meninas, não teria sido atropelado”. A sua diferença em relação aos outros meninos já era vista como um problema e isso já a fazia alvo de preconceitos.

Aos 14 anos, a cobrança de sua família para que ela se "comportasse como homem" se intensificou, ao ponto em que se viu na necessidade de fugir de casa. Deborah fugiu e foi acolhida por uma travesti, que se prostituía, inserindo Deborah nesse universo. Vivenciou diversos outros eventos emblemáticos até os 25 anos, quando começou a ter contato com grupos militantes LGBT, assim produzindo mudanças significativas em sua trajetória de vida.

Hoje em dia, Débora é ativista de movimentos populares e culturais, e se tornou coordenadora do Fórum Estadual LGBT no Espírito Santo, coordenadora adjunta da região sudeste da ABGLT e da Associação Nacional das Travestis (Antra).

Foi por intermédio de Deborah que fui apresentado a Crislaine. Nascida em 1976, atualmente residente na cidade de Serra, Crislaine é cabeleireira de formação. Natural de Brasília, viveu boa parte da sua vida no interior da Bahia. Criada por seus avós, sua infância foi marcada pelo contato com o espiritismo e pela ausência de seus pais, situação essa que é relembrada com profundo pesar, pois seu desejo era ter sido criada por seus genitores.

Sua família era muito preconceituosa, principalmente o seu avô. Crislaine lembra que ele, um policial, era uma pessoa muito severa e machista, ao ponto de expressar um profundo repúdio à homossexualidade, dizendo que seria capaz de matar aquele que em sua família fosse homossexual. Esse posicionamento de seu avô fez com que Crislaine crescesse num ambiente muito hostil, de medo constante, pois ela já sabia que não se enquadraria nos padrões que seu avô tinha como corretos.

Ao fugir de casa, Crislaine começou a se prostituir para conseguir sobreviver. Com a ajuda de uma amiga da escola, que lhe emprestou um quarto dos fundos para ela morar, conseguiu sobreviver à saída repentina da casa de sua avó. Novamente, assim como na trajetória de Deborah, o evento de fugir de casa aparece como um elemento importante para a possibilidade de se vivenciar o projeto de ser mulher.

O mais difícil para Crislaine em sua trajetória, depois de haver saído da casa de sua avó, foi a 
prostituição. Ela recorda que precisava manter relação com qualquer pessoa para que pudesse conseguir algum dinheiro que a mantivesse longe de seus familiares.

No início de 2011, ela realizou a cirurgia de transgenitalização. No mesmo ano, quatro meses depois do seu procedimento cirúrgico, ela foi presa, juntamente com o seu companheiro, sob a acusação de tráfico de drogas.

Esse fato em sua vida foi de extrema relevância, uma vez que, por conta dessa prisão, ela foi parar num presídio masculino. Antes disso, sofreu diversos tipos de constrangimentos e humilhações por parte da polícia. No ato de sua prisão, ela foi encaminhada à delegacia masculina de Cariacica, ocasião em que foi "avaliada" por vários policiais, visto que todos queriam "ter certeza" de que ela realmente era uma mulher. Apesar de já ter realizado a cirurgia na ocasião que foi presa, Crislaine, em seu corpo, enunciava uma série de experiências e marcas, ou seja, um corpo cartográfico. Mesmo depois de ter exposto seu corpo aos policiais da delegacia, foi encaminhada para o Centro de Detenção Provisória (CDP) masculino, onde novamente ela teve que se sujeitar às humilhações e aos constrangimentos de ter que expor seu corpo novamente para vários policiais da CDP. $\mathrm{Na}$ época, não havia no Estado nenhum caso como o de Crislaine e a lei não tratava sobre qual procedimento tomar em casos de mulheres transexuais detidas, ou seja, novamente a partir de uma trajetória individual vemos o alargamento do "campo de possibilidades" de ser mulher na sociedade capixaba.

Ao ser detida, Crislaine expõe ao Estado a necessidade de se reverem as leis referentes à prisão de pessoas que passaram pela cirurgia de transgenitalização, mas que ainda não mudaram o registro civil. Na época, o ocorrido fez com que a justiça liberasse uma liminar ordenando a sua transferência para o presídio feminino. Crislaine ficou detida durante dois anos. Hoje ela está em busca de um emprego, principalmente para conseguir manter o uso dos hormônios femininos.

Por intermédio de Crislaine se deu meu contato com Rafaela. Elas se conheceram nos encontros na HUCAM (Hospital Universitário Cassiano Antônio Moraes). Nossos encontros sempre se deram no Shopping Vitória, na praça de alimentação. A realidade social de classe média de Rafaela é um dos pontos que diferencia a sua história de tantas outras mulheres que vivenciam a transexualidade.

Rafaela nasceu em Linhares, em 1987, uma cidade de médio porte do norte do Espírito Santo. Filha de pais separados, desde cedo teve mais contato com seu padrasto do que com o seu pai, mas o relacionamento com este sempre foi tranquilo e sem conflitos. Desde sua infância, Rafaela recorda que sua aproximação com o universo feminino sempre foi muito forte. $\mathrm{O}$ início de sua adolescência foi um período de muitos conflitos internos, pois nessa fase de sua vida Rafaela ainda não conseguia se entender. As suas subjetividades ainda entravam muito em conflito com os padrões sociais que lhe eram imputados.

Por volta dos seus 17 anos, Rafaela foi levada por sua mãe ao psicólogo para tentar compreender as incompatibilidades de gênero que ela estava vivenciando - esse comportamento diferenciado era algo que incomodava a sua mãe. Nessa época, Rafaela já havia começado a tomar hormônios femininos sem que sua família soubesse. Ao descobrir, sua mãe entendeu que era necessário buscar ajuda médica. Foi por meio do tratamento com o psicólogo que ela recebeu o diagnóstico de que era uma pessoa que sofria com transtorno de gênero.

Apesar de ter fisicamente um corpo de mulher, Rafaela conta que antes da cirurgia era frustrada em suas relações amorosas e sexuais, pois os homens muitas vezes queriam que ela fosse ativa na relação. Ela também lembra que não conseguia se despir totalmente, pois não queria que seu órgão genital ficasse à mostra.

Dessa maneira, novamente a ideia de corpo cartográfico aparece na biografia de uma mulher na transexualidade, uma vez que, para Rafaela, o fato de os homens não a enxergarem como uma mulher e pedirem que ela os penetrasse era algo muito ofensivo. Essas situações geravam muito conflitos internos em sua vida, e foi assim que ela começou a buscar ajuda psicológica, a fim de que pudesse realizar a cirurgia de transgenitalização.

\section{3 - Relatos de vida de uma liminaridade}




\section{permanente}

Intensificando marcadores sociais da diferença, a liminaridade permanente produz uma vasta gama de experiências de exclusão e de estigmatização das pessoas que a vivenciam. Não somente isso: condiciona as pessoas transexuais à abjeção.

Dentro da lógica da ritualização da vida, como foi proposto, a etapa de separação e a agregação são, quase sempre, suprimidas na vida de muitas pessoas que vivenciam a transexualidade. Argumento dessa forma, pois, a partir dos relatos de vida que serão apresentados, podemos perceber que as interlocutoras deste trabalho ocuparam em diversos momentos um lugar liminar em nossa sociedade. Vemos isso, por exemplo, em suas infâncias, por apresentarem o rompimento com as "teias do gênero", experiência essa que diversas vezes em suas biografias foi significativa na configuração de suas identidades e subjetividades. Os relatos dessas mulheres nos evidenciam que a liminaridade produzida pela experiência transexual é um complicador em suas trajetórias. As experiências liminares tendem a se iniciar desde muito cedo, como podemos ver de maneira explícita nos relatos de Crislaine e de Deborah abaixo:

Com onze anos de idade, quando o meu avô descobriu, aí foi a gota d'água. Eu estava com onze anos de idade, eu já estava vestindo roupa de mulher. Eu peguei e contei pra ele que eu estava gostando de um coleguinha meu, que era vizinho da minha casa. Nós já não estávamos na Bahia mais, estávamos morando em Goiânia. Aí, o meu avô ficou revoltado, o meu avô já estava separado da minha avó [...] Aí quando o meu avô soube desse caso que eu tive com esse rapaz e que estava usando roupas de mulher, aí ele quis me matar. Bateu, me espancou! A mulher dele, a Esmeralda, que me defendeu no caso, assim, ele pegou um revólver pra me matar [...] Voltei pra casa da minha avó, cheguei na casa da minha avó, comecei a usar roupa da minha irmã e os tios começaram a querer me bater, né? Que era filho do meu avô, também era machista e aquela coisa toda. Eu saí de casa e fui morar sozinha com doze anos de idade. (Crislaine)

Foi exatamente no dia que o meu pai falou bem assim: "ou você entra como menino ou você não volta". Botou um pedaço de pau do lado de fora. Aí, eu não voltei mais. Dali mesmo eu me virei, comecei a rodar, pedindo na rua às pessoas. É... Eu acho, assim, que foi muita loucura minha. Eu saí de casa só com duas peças de roupa e eu lembro disso até hoje. Uma calça que eu tinha ganhado de uma pessoa e hoje voltou a moda. Uma calça laranja. Eu branca igual um sebo com uma calça laranja que eu tinha ganhado de uma pessoa e uma blusa preta. Sempre achei que o laranja combinava com o preto, né? Então, combinei. E uma roupa... Pois é, a única roupa que eu saí. Uma bolsa, uma sacola de supermercado, com um dinheirinho, como eu tinha trabalhado em algum lugar, eu juntei aquele dinheiro e fui pra rua [...] Acho que doze anos. E assim, eu fiz muita coisa, assim, minha vida foi muito louca assim, né? (Deborah)

Como já salientado, no período limiar, o "transitante" tem características ambíguas, passando por um domínio cultural que pouco ou nada tem dos atributos do passado ou futuro; encontra-se em posição intermediária, no limiar de uma a outra fase, à margem. Para Turner (1974, p. 117), "[...] as entidades liminares não se situam aqui nem lá; estão no meio e entre as posições atribuídas e ordenadas pela lei, pelos costumes, convenções e cerimonial". Todavia, no caso das entrevistadas, essa fase foi vivida desde quando eram muito novas. A ambiguidade é um traço marcante das suas vivências, como podemos perceber em trechos dos seus relatos: "aí ficavam as duas filas e eu no meio"; "ele dizia que não tinha neto que ficava em cima do muro"; "explicou que era como se eu tivesse um desencaixe"; tudo porque eu era diferente, eu era meio híbrida, não me adequava às expectativas deles". No decorrer da vida, a liminaridade permanente vai se materializando de diversas formas nas diversas instituições sociais. Os trechos a seguir nos permitem perceber essa situação:

[...] Eu lembro de não poder entrar na escola na mesma hora, porque antigamente batia o sinal e você tinha que ir pra fila pra cantar o hino nacional. E que fila que eu ficava? Que fila que eu ficava? Tinha que cantar o hino nacional, qual é a fila que eu ficava? Aí os meninos me empurravam "Aqui 
não, aqui não, aqui não!", entendeu? "Mariquinha, boiolinha, aqui não, aqui não". As meninas não deixavam eu ficar, aí o que que acontecia, eu empurrava, ofendia... Aí, a diretora tinha que me botar do lado dela ou a professora "Fica aqui! Fica aqui perto", aí ficavam as duas filas e eu no meio[...] (Deborah)

[...] Depois que fugi da casa dele, nunca mais cheguei a ver ele de novo. Eu fiquei sabendo que ele falou no testamento dele lá. Ele tinha fazendas, daí no testamento falaram que ele disse para os meus tios, com os meus parentes de lá, que não ia botar o meu nome no testamento dele, porque eu era tipo uma aberração. Uma aberração, pois ele dizia que eu nem era homem e nem era mulher, e ele não aceitava uma pessoa como eu, ele dizia que não tinha neto que ficava em cima do muro. (Crislaine)

[...] Quando você chega na adolescência, eu já estava meio que deixando o cabelinho crescer, a fazer unha, aí eu estava [...] que eu ainda não sabia realmente que eu queria ser uma mulher ou um homem. Ainda estava confuso na minha cabeça. Aí, quando eu cheguei, acho que foi aos dezessete anos, que minha mãe me levou ao psicólogo, pra poder entender por que eu estava ficando tanto diferente, eu já estava começando a tomar hormônio escondida, daí o meu corpo estava ficando feminino, a minha aparência era uma mistura de menina com menino. Daí a minha mãe me levou no psicólogo para saber por que eu estava ficando estranha. Aí o psicólogo começou a fazer tratamento comigo, aí falou que eu tinha transtorno de gênero, explicou que era como se eu tivesse um desencaixe. (Rafaela)

[...] Oitenta e oito aconteceu uma cena inacreditável, que essa eu marquei essa cena até hoje. Eu sempre fui do choque, mesmo. Eu lembro que eu acordei cedo, eu tinha um cabelo de franjão, assim, era um cabelo de franja, assim, lisa, meu cabelo todo, assim, fechado, escovado. Eu coloquei uma calça dessa, eu coloquei a camisa do uniforme e esse dia eu coloquei uma outra blusa por baixo que fechava a gola até aqui em cima e colocava uma cruz pequena aqui e um rayban. Quando eu cheguei na porta da escola, aonde as pessoas se formavam pra poderem entrar na escola, eu tive uma vaia gigante, uma onda gigante, uma coisa gigante. Uma professora chegou pra mim e falou: "Nossa, foi só por causa disso que eles todos gritaram lá embaixo?”. Tudo porque eu era diferente, eu era meio híbrida, não me adequava às expectativas deles, daí para eles eu não podia estar ali junto com eles, como se a minha presença atrapalhasse a harmonia da escola. (Sandy)

A partir desses relatos conseguimos notar o estado de liminaridade - estado de transição entre duas fases -, ou seja, os indivíduos não "pertencem" à sociedade a que antes faziam parte e ainda não foram reincorporados a outra. A referência de pertencer, que pretendo aqui, está diretamente ligada à noção de enquadramento, ou seja, a transexualidade é percebida como uma experiência que impede a agregação de quem a vive em nosso contexto social.

Alguns trechos deixam bem evidentes essa fase na vida das minhas entrevistas. Deborah nos relatou que, quando criança, na escola, ao formar fila para cantar o hino nacional, ficava no meio, pois não era aceita na fila dos meninos ou das meninas. Crislaine nos relata que o seu avô a tinha como aberração, pois ele não a via nem como homem nem como mulher. Sandy também nos contou que quando criança e adolescente promovia conflitos na escola por ser híbrida. Já a mãe de Rafaela, ao notar a diferença no comportamento de sua filha, procurou um psicólogo, sendo diagnosticada como possuidora de transtorno de gênero.

As trajetórias de vida das minhas entrevistadas nos permitem perceber a experiência da liminaridade, que é permanente, esse momento em que o limbo é vivenciado, um período ambíguo, transitório, caracterizado pela humildade, reclusão. De alguma maneira, é na adolescência que o conflito se estabelece mais intensamente, pois é nessa fase que as diferenciações de gênero se acentuam na vida de homens e de mulheres, tanto nas mudanças corporais quanto nas performances que homens e mulheres precisam assumir em nossa sociedade. Turner considera que "fases e pessoas [liminares] podem ser muito criativas em sua libertação dos controles estruturais, ou podem ser consideradas perigosas do ponto de vista da manutenção da lei e da ordem." (TURNER, 1974, p. 6).

Como dito, apesar de serem empurradas para uma condição liminar de existência, as mulheres transexuais criam estratégias diversas 
para tentarem sair dessa condição. Desse modo, a criatividade é algo muito presente na vida de mulheres na transexualidade; entendendo criatividade como inventar algo novo, elas constantemente precisam se reinventar como pessoas. Principalmente precisam criar novas formas de vivenciar o ser mulher, rompendo com padrões de feminilidade que perpassam o corpo. Assim, elas apresentam ou visibilizam novas possibilidades de ser mulher em nossa sociedade, ou até mesmo revelam para nós feminilidades que são invisibilizadas devido aos estereótipos do que é ser mulher, difundidos pelos discursos hegemônicos.

A liminaridade é condição de existência imposta cotidianamente a inúmeras mulheres transexuais, por isso a entendo como permanente, pois a transgenitalização nem sempre é capaz de inseri-las na sociedade com o novo papel social que é almejado e "prometido" por essa cirurgia. O papel de mulher, apenas mulher, sem nenhum adjetivo a esse substantivo. Sandy, no trecho a seguir, nos mostra como a cirurgia não consegue reagregação na sociedade como status de mulher. Ela havia dito que, se uma mulher na transexualidade coloca na cabeça que é homem operado, ela vai ser um homem operado.

Julgamento é de cada um, você está entendendo? Se ela se sente mulher e ela se... se há dentro da proposta dela pra adequá-la, mas se ela coloca na cabeça dela que "Ah, eu sou um homem operado", ela vai ser um homem operado, está entendendo? Porque é um julgamento da própria pessoa. (Sandy)

Mas, ao ser questionada se esse julgamento era imposto pela sociedade, Sandy respondeu:

Ah, eu acredito que sim. Acredito que sim, sabe o por quê? Quem faz uma correção como essa, a primeira coisa pra você não ter chatices é você ter que mudar de país. Sumir. Vá embora. Desaparece! [...] Foi por isso que eu fui para a Europa. Me incomodava muito. Por exemplo, eu estava numa festa, eu poderia não estar a fim do rapaz que estava encostado naquele balcão, mas ele começava a conversar comigo, alguém tinha que se aproximar dele e avisar a ele que eu era um travesti, você está entendendo? Era uma maldade muito grande, como deve acontecer com outras pessoas. Comigo já não acontece mais, porque eu fiquei muito tempo longe do Brasil, entende? Mas, eu acredito que acontece essa maldade, entendeu? Porque no meu período foi isso que aconteceu. Como foi um "boom" muito grande, as pessoas queriam te atingir, colocavam o dedo na sua ferida, te machucar, entendeu?

"Ah, está dando tudo certo pra você aqui? Mas a sua vida pessoal vai ser uma merda!", você está entendendo? (Sandy)

A partir dos relatos acima, podemos perceber como a condição de liminaridade na vida das mulheres transexuais pode ser entendida como difícil de se transpor dentro da lógica social binária na qual a sociedade ocidental se estabelece. E essa condição limita a ação dessas mulheres em nossa sociedade. Esse não lugar que é a liminaridade se torna um lugar de profunda reflexão, conforme aponta Turner:

[...] são segregados de suas posições estruturais e dos valores, normas, sentimentos e técnicas associados com essas posições. São, igualmente, despidos dos hábitos prévios de pensamento, sentimento e ação. Durante o período liminar, são forçados e encorajados a refletir sobre sua sociedade, seu cosmo, e os poderes que os geram e sustentam. A liminaridade pode ser descrita como um estágio de reflexão. Nele, aquelas ideias, sentimentos e fatos que até aqui tinham aparecido enfeixados em configurações e foram aceitos sem pensar, são, por assim dizer, decompostos em seus elementos. Esses elementos são isolados e transformados em objetos de reflexão por meios de processos como o exagero dos componentes e a dissociação por variações concomitantes (TURNER, 1974, p.151).

Turner (1974) aduz que o período liminar irá trazer consigo a possibilidade da reflexão, juntamente com o surgimento de novas configurações sociais e interpretações do mundo. Esse processo no qual os elementos tornam-se objetos de reflexão promove novas relações e interpretações do homem com as coisas do mundo, estabelecendo a renovação do pensamento e do próprio viver.

No caso das mulheres na transexualidade, em especial as interlocutoras, podemos notar que essa reflexão de seus lugares na sociedade é 
cotidiana, pois, recorrentemente, elas precisam buscar uma reflexão de quem elas são na sociedade, especialmente no que se refere a criar possibilidades, além da categorização biológica para vivenciarem a experiência de ser mulher. Essa reflexão é necessária, uma vez que a experiência de ser mulher precisa ser satisfatória, mesmo numa sociedade que irá, recorrentemente, negar a essas mulheres essa identidade.

A liminaridade permanente na vida das mulheres na transexualidade promove uma constante reflexão sobre como viver numa sociedade que, recorrentemente, coloca em xeque a experiência identitária dessas mulheres como sendo possível. Sandy nos traz algumas falas que nos permitem perceber essa reflexão constante.

Eu me julgo uma pessoa muito moderna. Eu acho assim, que as pessoas podem fazer o que elas acharem. Que o que tá dando vontade de elas fazerem naquele momento. Só que eu acho que é uma insegurança. É uma insegurança. Se eu passar na rua e todo mundo começar a gritar comigo, aquilo não vai me atingir, você está me entendendo? Mas, tem muita gente que não. Às vezes, estão tão mal resolvidas consigo mesmas que, às vezes, tem um rapaz ou outro comentando alguma coisa deles e dão uma gargalhada, as pessoas já assimilam aquilo como algo ruim, ficam depressivas, pois elas acham que é a sociedade que tem que falar para elas que elas são mulheres. Mas na verdade quem precisa se achar mulher são elas. Se eu não me ver como mulher, não vai ser a sociedade que vai me ver. (Sandy)

Essa reflexão que a liminaridade na experiência da transexualidade traz é importante, uma vez que as pessoas que a vivenciam precisam reelaborar a sua experiência, de maneira a buscar referências outras que não as estabelecidas pela sociedade, ou ressignificar as referências existentes. As mulheres na transexualidade estão constantemente nesse processo de ressignificar a experiência de "ser mulher". Mas, apesar da liminaridade promover essa possibilidade de pensar e reelaborar a experiência de ser mulher, alguns marcos socioculturais (as noções socialmente aceitas de gênero, corpo e sexualidade) do universo simbólico do "ser mulher” serão sempre utilizados na configuração dessa experiência identitária.

\section{Considerações finais}

O que vemos, então, é que as mulheres transexuais são limitadas em sua atuação na sociedade, uma vez que estamos inseridos numa sociedade capitalista, na qual nossa posição no mercado nos diz quem somos ou se estamos inseridos na dinâmica social. As mulheres na transexualidade muitas vezes são impossibilitadas de almejarem posições outras que não as já "estabelecidas" para elas. A prostituição é um fato, situação essa vivida por Deborah e Crislaine. Outra posição a que mulheres transexuais geralmente são direcionadas está relacionada com o universo da estética e da beleza. Rafaela é uma das muitas mulheres na transexualidade que conseguiram se estabelecer profissionalmente, trabalhando em salões de beleza. No meio artístico, como podemos ver no exemplo de Sandy, também é aceitável que mulheres na transexualidade estejam presentes, mas com menos intensidade.

Obviamente, não estou querendo ser pragmático ao falar dos lugares sociais que essas mulheres ocupam, é fato que várias não ocupam esses locais, mas que, de maneira geral, a maior parte das mulheres na transexualidade é direcionada para uma condição de subalternidade social.

A minha compreensão, para além do reconhecimento que o movimento LGBT busca, é o que as mulheres transexuais, às vezes, estão em busca. A satisfação psicossocial, em muitas situações, fala mais alto do que as lutas políticas. Obviamente, não estou dizendo que uma situação não tem nada com a outra. As lutas políticas são importantes, mas nem sempre serão representativas para essas mulheres, ou são entendidas como interligadas às suas necessidades cotidianas.

Quando falo de satisfação psicossocial, estou entendendo isso como eventos nas trajetórias de nossas vidas, que fazem com que as nossas experiências sejam significativas para além dos percalços e dos eventos negativos que marcam o nosso trajeto. Um exemplo de satisfação psicossocial é o relato de Rafaela, abaixo:

Ontem mesmo eu fui na praia, pude botar um 
biquíni, coisa que eu nunca podia fazer à vontade, entendeu? São coisas simples na vida, mas que faz uma grande diferença pra quem é transexual operada, entendeu? Não é, tipo assim, que a cirurgia vai ser a solução da minha vida. Não vai ser. Talvez esses problemas podem dificultar mais ainda daqui pra frente, entendeu? Mas eu fiz já sabendo que seria dessa forma. (Rafaela)

A satisfação psicossocial está embutida no projeto de vida que não necessariamente passará por uma militância de movimentos sociais pelo reconhecimento da transexualidade, uma vez que mulheres transexuais, muitas vezes, não buscam serem vistas como transexuais, mas apenas como mulheres. Todavia, como já foi dito anteriormente, de acordo com Velho (2013), um projeto coletivo não vai ser vivido de modo totalmente igual pelos indivíduos que o compartilham.

Por exemplo, há poucos anos no Brasil tivemos o caso do possível envolvimento amoroso do ex-jogador de futebol Romário com a modelo Thalita Zampiroli, caso esse que foi evidenciado pela mídia, principalmente porque Thalita é uma mulher na transexualidade. Nas matérias publicadas ${ }^{8}$ sobre o envolvimento do ex-jogador com a modelo, era visível o tom preconceituoso e jocoso que foi dado ao caso.

A maior parte dos veículos midiáticos tratou o possível relacionamento do Romário com Thalita como se ele estivesse se envolvendo com um ser "alienígena". Só o fato de perguntar se havia beijo na boca entre eles demonstra a assepsia social que se tem com as pessoas transexuais. A todo momento, questionamentos em tom agressivo foram disparados à modelo, sem nenhuma consideração que determinadas perguntas poderiam ofender e serem desrespeitosas para uma pessoa que busca seu reconhecimento como uma mulher: "qual é o seu nome de batismo?", "ninguém diz que você é transexual, ou diz?". A necessidade de saber o nome de batismo demonstra que, apesar da estética corporal dizer que Thalita é uma linda mulher, não é o bastante, pois ela carrega consigo uma imposição biológica e social que, recorrentemente, será evocada para dizer que ela não é uma mulher, apesar de ter se sujeitado a uma cirurgia de transgenitalização.

O histórico amoroso de Romário é vasto e, atualmente, a mídia nem estava mais se atendo aos seus romances, mas como dessa vez havia uma particularidade, o caso foi exageradamente noticiado por ela. E nessa superexposição, surgiram vários comentários que revelam a noção asséptica que a nossa sociedade ainda tem sobre as pessoas transexuais.

Frases como "Romário pegando traveco", "Quem diria! Romário que sempre foi um cara machão", "Nada contra a opção homossexual, mas a gente se surpreende quando descobre que uma pessoa do perfil do Romário faz essa opção" nos fazem ver que a identidade feminina da mulher transexual não é tida como legítima, pois ainda se entende que a mulher transexual é um fake, alguém que está se passando por algo que não é.

Um dos pontos altos desse caso foi a manifestação do Romário sobre a polêmica. O ex-jogador declarou numa rede social que Thalita era sua camarada, disse ainda que respeita o gosto pessoal de qualquer pessoa, mas disse enfaticamente - "ela não é mulher (...) mas volto a afirmar: eu gosto de mulher". Nesse pequeno relato sobre um dos vários casos de personalidades midiáticas que teriam relacionamentos com mulheres na transexualdiade, exemplifica-nos a condição liminar produzida pela transexualidade.

8 Sobre o caso, segue alguns links de reportagens:

Link 1:

http://noticias.bol.uol.com.br/ultimas-noticias/entretenimento/2014/02/11/namorei-romario-durante-um-ano-revelatransexual-thalita- zampirolli.htm/. Acesso em: 10 jan. 2018.

Link 2:

http://ego.globo.com/famosos/noticia/2014/02/eu-namorei-romario-durante-um-ano-diz-transexual-thalita-zampirolli.htm. Acesso em: 10 jan. 2018.

Link 3:

http://igay.ig.com.br/2013-12-17/romario-nega-romance-com-modelo-trans-thalita-zampirolli.html. Acesso em: 10 jan. 2018.

Link 4:

http://esporte.uol.com.br/ultimas-noticias/2014/04/02/romario-consegue-na-justica-proibir-transexual-de-falar-sobre-supostocaso.htm 
Ao longo deste trabalho, tive como objetivo trazer relatos de vida de pessoas que nasceram com corpos categorizados pela medicina como masculinos, mas que desejaram tornar-se mulher, tomando como elemento norteador a ideia de que tal experiência pode conduzir os indivíduos que a vivenciam a uma condição liminar. A partir dos relatos de vida de quatros mulheres, eu pude captar categorias importantes do que é entendido por ser mulher em nossa sociedade, principalmente notar que esse processo de construção é infinito na vida delas, e os seus projetos individuais sempre estarão em constante reformulação e reatualização, uma vez que elas precisam sempre estar em devotada atenção para a eliminação de algum traço que possa evidenciar uma não feminilidade e numa tentativa constante de superar a condição liminar de suas experiências.

Em suma, a liminaridade permanente na vida das mulheres na transexualidade tende a impossibilitar as ações e o trânsito dessas mulheres em nossa sociedade, o que limita o campo de atuação delas, em especial no que se refere ao campo de satisfação psicossocial. A liminaridade na vida das mulheres na transexualidade também cria duas situações distintas: a invisibilidade, que deve ser entendida como a não consideração que essas mulheres são dignas de direitos e respeito, e, por outro lado, existe a situação da hipervisibilidade, que seria um excesso de visibilidade numa dimensão negativa, pois essas mulheres são retratadas de maneira caricata, não humana, patológica. $\mathrm{E}$, sendo assim, essa experiência se coloca como intensificadora de marcadores sociais que promovem desigualdade e acentuam a estigmatização.

\section{Referências Bibliográficas}

AMANTINO, Márcia. "E eram pardos, todos nus, sem coisa alguma que lhes cobrisse suas vergonhas". In: História do corpo no Brasil. São Paulo: Editora Unesp, 2011. Cap. 1. p. 15 - 43

BENTO, Berenice. O que é transexualidade. São Paulo: Brasiliense; 2008.
BRANDÃO, Junito de Souza. Mitologia Grega. Vol II. 12a Ed. Petrópolis: Ed. Vozes: 2001.

BURTLER, Judith. Problemas de gênero: Feminismo e subversão da identidade. Rio de Janeiro: Editora Civilização Brasileira: 2003.

CHILAND, Colette. O transexualismo. São Paulo: Edições Loyla: 2008.

CLASTRES, Pierre. A Sociedade contra o Estado. São Paulo. Cosac Naify, 2003.

COSSI, Rafael Kalaf. Transexualismo, psicanálise e gênero: do patológico ao singular. $151 \mathrm{f}$. Dissertação (Mestrado em Psicologia Clínica) Instituto de Psicologia, USP, São Paulo, 2011.

FOUCAULT, Michel. História da sexualidade 1: A vontade de saber. 3. ed. Rio de Janeiro: Graal, 1980.

(1982).'Le sujet et le pouvoir". In: Dits et écrits, v. IV (1980-1988). Paris: Gallimard, 1994.

GARCIA, Agnaldo; SOUZA, Eloisio Moulin de. "Sexualidade e trabalho: estudo sobre a discriminação de homossexuais masculinos no setor bancário". Revista de Administração Pública. Rio de Janeiro, 44 (6): 1353- 1377, Nov./ Dez. 2010.

GEERTZ, Clifford. A interpretação das culturas. RJ: LTC, 1978.

IRIGARAY, Helio Arthur Reis. "Estratégia de sobrevivência dos gays no ambiente de trabalho". In: XXXI ENANPAD, 2007.

"Identidades sexuais não-hegemônicas: a inserção dos travestis e transexuais no mundo do trabalho sobre a ótica queer". In: Encontro de Estudos Organizacionais, 06, 2010, Florianópolis. Anais. Florianópolis: ANPAD, 2010.

IRIGARAY, Helio Arthur Reis; FREITAS, Maria Ester de. "Sexualidade nas organizações brasileiras: estudos sobre Ser gay nas organizações contemporâneas". XXXI ENANPAD, 2007.

IRIGARAY. Helio Arthur Reis; SARAIVA, Luiz Alex Silva; CARRIERI, Alexandre de 
Pádua. "Humor e discriminação por orientação sexual no trabalho". Revista de Administração Contemporânea. Curitiba, 14 (5): 890 - 906. Set/ Out. 2010.

LAQUEUR, Thomas Walter. Inventando o sexo corpo e gênero dos gregos a Freud. Rio de Janeiro: RelumeDumará, 2001.

LE BRETON, David. Sinais de identidade: tatuagens, piercings e outras marcas corporais. Trad. Tereza Frazão. Lisboa: Miosótis, 2004.

MOTT, Luiz. "A homossexualidade entre os índios do Novo Mundo antes da chegada do homem branco". BRITO, Ivo et al. Sexualidade e saúde indígenas. Brasília: Paralelo 15, 2011.

PEREIRA, Carolina Grant. "Bioética e Transexualidade: Para além da patologização, uma questão de identidade de gênero". Trabalho publicado nos Anais do XIX Encontro Nacional do CONPEDI realizado em Fortaleza - CE nos dias $09,10,11$ e 12 de Junho de 2010.

RAMSEY, Gerald. Transexuais perguntas $e$ respostas. São Paulo: Summus, 1998.

ROCHA, Everardo. O que é mito. Coleção Primeiros Passos 151. Brasiliense, 1991.

SAADEH, Alexandre. Transtorno da identidade sexual: Um estudo psicopatológico de transexualismo masculino e feminino. $279 \mathrm{f}$. Tese (Doutorado em Psiquiatria) - Faculdade de Medicina, USP, São Paulo, 2004.

SIQUEIRA, Marcus Vinicius Soares; SARAIVA, Luiz Alex Silva; CARRIERI, Alexandre de Pádua; LIMA, Helena Karla Barbosa de; ANDRADE, Augusto José de Abreu. "Homofobia e violência moral no trabalho no distrito federal. Organizações e Sociedade". Salvador: 16 (50): 447-461. Jul./Set., 2009.

SOUZA. Eloísio Moulin; PEREIRA, SEVERINO JOAQUIM NUNES. "As categorias identitária que (re)produzem discriminações: estudo da discriminação exercida por gays”. In: ENANPAD,
34, 2010.

THÉVET, André. Singularidades da França Antarctica. São Paulo: Cia. Editora Nacional, 1944.

TREVISAN, João Silverio. Devassos no paraíso: A homossexualidade no Brasil. Rio de Janeiro. Record: 2002.

TURNER, Victor. O processo ritual. Petrópolis: Ed. Vozes, 1974. p. 116-159.

VAN GENNEP, Arnold. Os Ritos de Passagem. Petrópolis: Ed. Vozes, 1978.

VELHO, Gilberto. Antropologia urbana: cultura e sociedade no Brasil e em Portugal. Rio de Janeiro: J. Zahar, 1999.

Zahar, 2008. . Individualismo e Cultura. Rio de Janeiro, . Um antropólogo na Cidade: ensaios de antropologia urbana. Rio de Janeiro: Zahar, 2013.

ZAMBRANO,Elizabeth.Trocandoosdocumentos: Um estudo antropológico sobre a cirurgia de troca de sexo. 126 f. Mestrado (Antropologia Social) - Instituto de Filosofia e Ciências Humanas, UFRGS, Porto Alegre, 2003. 
